\title{
Study of Cognitive and Psychiatric Dysfunction in Children with Epilepsy
}

\author{
*DR. Snehalatha.Gopu ${ }^{1}$, DR. Usha Rani.H ${ }^{2}$, Dr. MuraliRao.G ${ }^{3}$ \\ ${ }^{I}$ Assistant Professor of Pediatrics, Nilofer Hospital, Hyderabad, Telangana. \\ ${ }^{2}$ Senoir Resident ofPediatrics Nilofer Hospital, Hyderabad, Telangana. \\ ${ }^{3}$ Professor of Pediatrics, Nilofer Hospital, Hyderabad, Telangana. \\ *Corresponding author: DR. Usha Rani.H*
}

\begin{abstract}
Back ground: Epilepsy is one of the most physically and psychosocially debilitating chronic illnesses in children. A considerable proportion of children with epilepsy have various other disorders such as ADHD, learning problems, psychosocial difficulties, mental retardation, cerebral palsy or other disabilities.

Objective: To assess the prevalence of cognitive and psychosocial dysfunction in children with epilepsy aged 6 14 yrs.

Methodology: This is a cross sectional hospital based the study, included 100 children with age group ranging from 6 - 12 yrs., attending the neurology outpatient services for epilepsy. Cognitive assessment of the children was done by adopting the MISIC (Malins Intelligence Scale for Indian Children) scale. Psychosocial assessment was done by adopting the Developmental Psychopathology Checklist for children (DPCL)

Results:Psychosocial dysfunction is observed in 36\% of children with epilepsy. The prevalence of various disorders found in epilepsy patients are Learning disorders 30\%, Emotional disorders 21\%, Conduct disorders 5\%, ADHD was $12 \%$ and Psychoses was $1 \%$.
\end{abstract}

Conclusion: Cognitive and psychosocial dysfunction are the major comorbid disorders in children with epilepsy.

Keywords: children, cognition, epilepsy.

\section{Introduction}

Epilepsy is a chronic condition characterized by repeated occurrence of unprovoked seizures ${ }^{(\mathbf{1})}$. It is a neurological condition that affects the central nervous system and has various origins, symptoms, courses, and prognoses.Prevalence rates of childhood epilepsy reported from different countries have shown a wide variation with most clustering around 4-6 per 1,000 children ${ }^{(2)}$. Epilepsy is a chronic disorder that significantly affects cognitive and psychological domains ${ }^{(3)}$. Cognitive functions can already be impaired at the onset of the disease and the maturation of the cognitive functions in children is susceptible to the adverse influence of epilepsy ${ }^{(4)}$. More up to date research has revealed the complexity of the disorder with involvement of neurological, neuropsychological and psychosocial factors ${ }^{(3,5)}$. Psychosocial and cognitive functions are, apart from control of seizures, two of the most important determinants of quality of life in a child with epilepsy ${ }^{(\boldsymbol{)}}$. There are very few studies from developing countries that had studied the effect of seizures on these domains. The present study was hence taken up to evaluate the cognitive and psychosocial dysfunctions in children with epilepsy aged 6 - 14 years.

\section{Aims and Objectives}

Primary Objective: To assess the prevalence of cognitive and psychosocial dysfunction in children with epilepsy aged 6 - 14 yrs.

Secondary Objective:To assess the effect of various seizure variables like

1.Type of seizure,

2. Age at onset of seizures,

3. Total duration of epilepsy,

4. Duration of each episode,

5. Frequency of seizures in the last year,

6.Usage of AED

7. Compliance of AED on the cognitive and psychosocial functioning in children with epilepsy.

\section{Materials and Methods}


This is a cross sectional hospital based study conducted at the Institute of Child Health, Niloufer Hospital, and Hyderabad. The study population included 100 children with age group ranging from 6 - 12 yrs, attending the neurology outpatient services from April 2010 to April 2011.

\section{Inclusion criteria:}

All children with epilepsy in the age group $6-14$ yrs.

\section{Exclusion Criteria}

1. Prior mental retardation before the onset of epilepsy

2. Structural malformations of the brain.

3. Provoked seizures due to trauma, meningitis, encephalitis, abscess etc.

4. Acute encephalopathy

Detailed history regarding the presenting history, past history, drug history, family history, demographic data were recorded. Thorough physical examination and complete neurological examination was done. Venous blood sampling and Cerebrospinal fluid analysis were done where ever necessaries and CT scan study of the Brain was obtained. Cognitive assessment of the children was done by adopting the MISIC (Malins Intelligence Scale for Indian Children) scale, which is the Indian adaptation of WISC (Wechsler's Intelligence Scale for Children). TheScale comprises 11 subtests divided into Verbal and Performance groups(table1). The MISIC scale has an inbuilt age wise scoring system. The raw scores of each test are directly converted to "Test Quotients" by means of tables, which are actually "Intelligence Quotients" (IQ's). The subtest TQ's are then added and group averaged (Verbal, Performance) and the Total or full-scale IQ's is obtained by the average of Verbal IQ (VQ) and Performance IQ (PQ). Based on the IQ levels, children were classified into mentally retarded (IQ < 69), borderline (70- 79), Low average (80 - 89), average and above (90 - 109). Psychosocial assessment was done by adopting the Developmental Psychopathology Checklist for children (DPCL) containing 124 items and six subsections.

\section{The subsections are:}

1.Developmental History

2.Developmental problems

3.Psychopathology

4.Family history

5.Stressors

6.Temperament

Table1

\begin{tabular}{|l|l|l|}
\hline & Verbal & Performance \\
\hline 1 & Information & Picture completion \\
\hline 2 & Comprehension & Block design \\
\hline 3 & Arithmetic & Object assembly \\
\hline 4 & Similarities & Coding \\
\hline 5 & Vocabulary & Mazes \\
\hline 6 & Digit Span & \\
\hline
\end{tabular}

\section{Results}

Statistical analysis was done using SPSS Version 16.0 (Statistical Package for Social Sciences). The tests employed were Student T test, Anova and Chi - Square test. The total number of children included in this study were 100.Mean age of patients included in this study was 9.66 yrs. with standard deviation of 2.21. Among the patients studied, 58 were males and 42 were females. Male: female ratio is $1.38: 1$. The mean IQ in the studied population was $79.80 \pm 11.94$.

$23 \%$ of children had extremely low IQ (69 \& below).

$23 \%$ had borderline IQ (70 - 79).

$33 \%$ had low average IQ (80 - 89).

$21 \%$ had average IQ (90 - 109).

Mean IQ among males was 81.34. Mean IQ among females was 77.66. The difference in sex with respect to IQ was not statistically significant. 55 cases $(55 \%)$ belonged to rural area and 45 cases (45\%) belonged to urban area. Mean IQ among children who belonged to rural area was 79.76 and that among urban area was 79.84. The difference in IQ between the 2 groups was not statistically significant.47 cases $(47 \%)$ belonged to lower class, 27 cases (27\%) belonged to upper lower class, 25 (25\%)cases belonged to lower middle 
class, $1(1 \%)$ case belonged to upper middle class. The difference in IQ among the different socioeconomic classes was not statistically significant $(\mathrm{p}>0.05)$.

GTCSconstituted 65\%(mean IQ 78.11), Complex partial seizures constituted 26\% (mean IQ 83.65), Simple partial seizures 4\%(mean IQ 83.50), Other types constituted 5\%(mean IQ 78.80). The difference in IQ among different types of seizures was not statistically significant $(\mathrm{P}>0.05)$ Average age at onset of seizures was 6.75 yrs. Age at onset of seizures was less than 5 years in 33\% cases and more than 5 years in $67 \%$ of cases. The difference in IQ was statistically significant $(\mathrm{p}<0.05)($ table 2$)$

Table 2: Age at onset and IQ levels

\begin{tabular}{|l|l|l|l|}
\hline $\begin{array}{l}\text { Age at } \\
\text { onset of } \\
\text { seizures }\end{array}$ & $\begin{array}{l}\text { Number of } \\
\text { cases }\end{array}$ & Mean IQ & $\begin{array}{l}\text { Std } \\
\text { deviation }\end{array}$ \\
\hline$<5$ yrs & 33 & 69.00 & 9.660 \\
\hline$>5$ yrs & 67 & 85.12 & 9.041 \\
\hline
\end{tabular}

Total duration of epilepsy was $<2$ yrs in 54\%, $2-6$ yrs in $33 \%, 6-10$ yrs in $12 \%,>10$ yrs in $1 \%$. The difference in IQ was statistically significant $(\mathrm{p}<0.05)($ table 3$)$

Table 3: Total duration of epilepsy and IQ levels

\begin{tabular}{|l|l|l|l|}
\hline $\begin{array}{l}\text { Total duration } \\
\text { of epilepsy }\end{array}$ & $\begin{array}{l}\text { Number of } \\
\text { cases }\end{array}$ & Mean IQ & Std deviation \\
\hline$<2$ yrs & 54 & 84.48 & 9.33 \\
\hline $2-6 \mathrm{yrs}$ & 33 & 78.45 & 11.14 \\
\hline $6-10 \mathrm{yrs}$ & 12 & 63.33 & 9.11 \\
\hline$>10 \mathrm{yrs}$ & 1 & 69.00 & - \\
\hline
\end{tabular}

Average duration of each seizure was less than $30 \mathrm{~min}$ in $71 \%$ and more than $30 \operatorname{minin} 29 \%$. The difference in IQ was statistically significant $(\mathrm{p}<0.05)($ table 4$)$.

Table 4: Average duration of each seizure and IQ levels

\begin{tabular}{|l|l|l|l|}
\hline $\begin{array}{l}\text { Duration of } \\
\text { each seizure }\end{array}$ & $\begin{array}{l}\text { Number of } \\
\text { cases }\end{array}$ & Mean IQ & $\begin{array}{l}\text { Std } \\
\text { deviation }\end{array}$ \\
\hline$<30 \mathrm{~min}$ & 71 & 81.31 & 11.18 \\
\hline$>30 \mathrm{~min}$ & 29 & 76.10 & 13.09 \\
\hline
\end{tabular}

Frequency of seizures in the last year was $<1$ in $5 \%, 1-6$ in 50\%, $6-12$ in $24 \%,>12$ in $21 \%$

Figure 1: Frequency of seizures and IQ levels

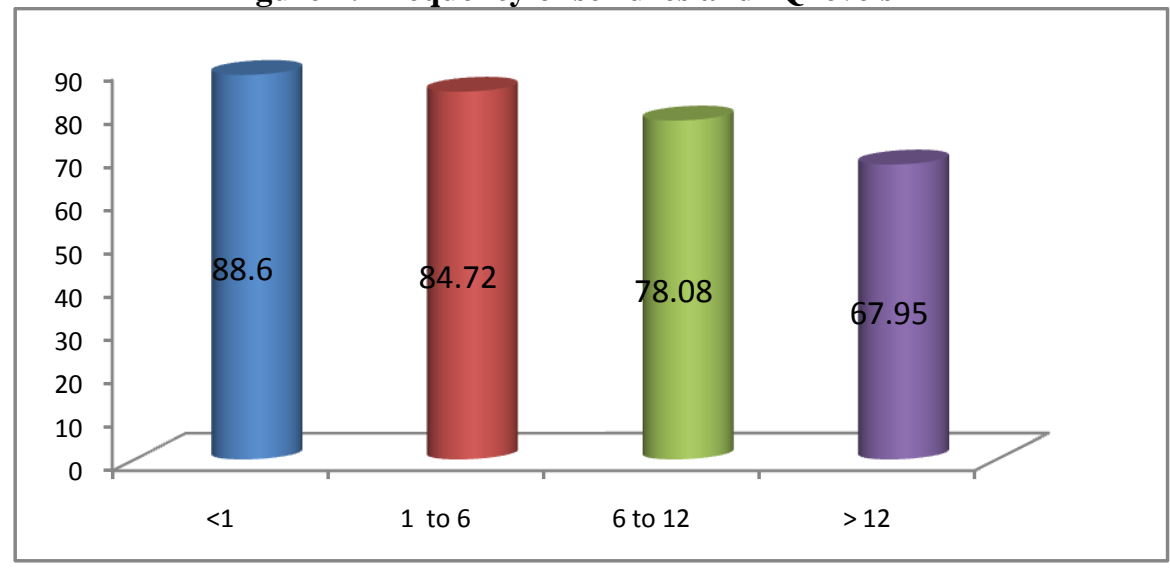


As the seizure frequency increased, there is a corresponding decline in the IQ levels and the difference was statistically significant(fig1).

Out of 100 cases $60 \%$ were on monotherapy, $18 \%$ were on polytherapy and $22 \%$ of children were not using any AED.The difference in IQ was statistically significant $(\mathrm{P}<0.05)$.

Table 5: Use of AED and IQ levels

\begin{tabular}{|l|l|l|l|}
\hline AED & $\begin{array}{l}\text { Number of } \\
\text { cases }\end{array}$ & Mean IQ & Std. deviation \\
\hline Monotherapy & 60 & 80.15 & 11.68 \\
\hline Polytherapy & 18 & 70.56 & 9.99 \\
\hline Not using & 22 & 86.41 & 9.42 \\
\hline
\end{tabular}

Out of 78 cases who received AED,30 cases were compliant (mean IQ 87.30), 48 cases were noncompliant (mean IQ 72.08). Children who were compliant had higher IQ levels than those who were noncompliant and the difference in IQ was statistically significant $(\mathbf{P}<\mathbf{0 . 0 5})$.

Psychosocial dysfunction was observed in 36\% of children. Among these $24(66.6 \%)$ were males, $12(33.3 \%)$ were females.The prevalence of various disorders wasLearning disorders 30\%,Emotional disorders $21 \%$,Conduct disorders was 5\%,ADHD was $12 \%$ and ,Psychoses was $1 \%$.

Figure 2: Prevalence of psychiatric disorders

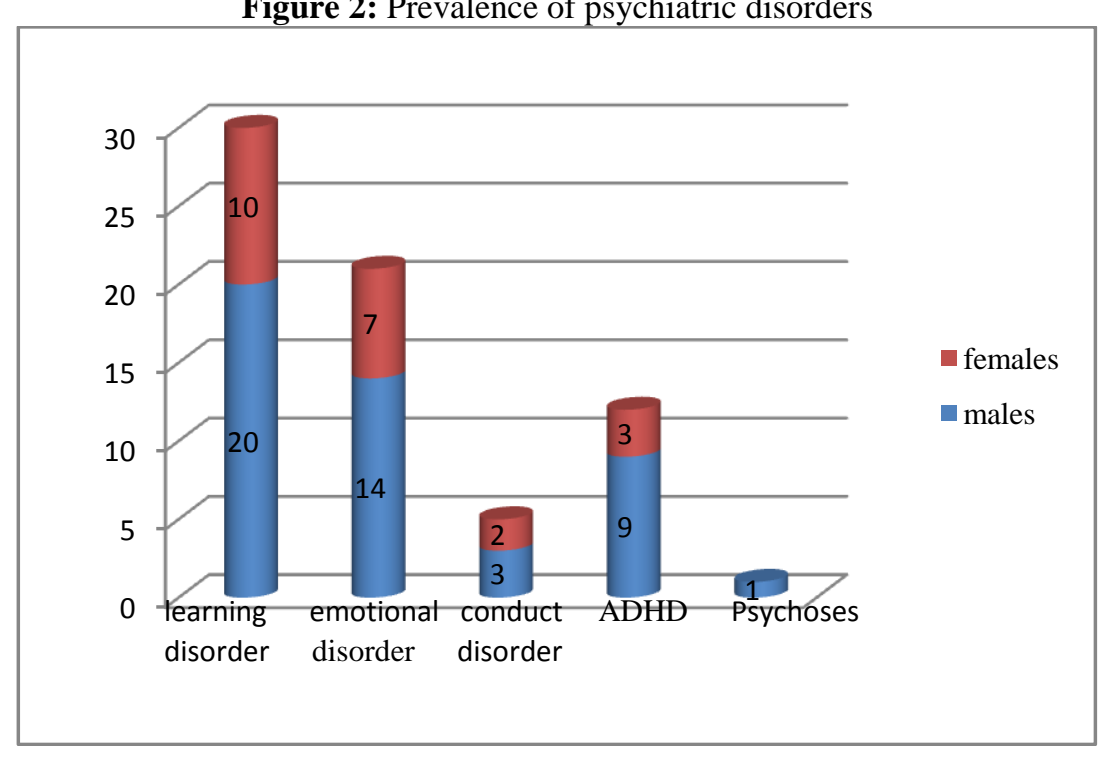

Out of 36 cases, GTCS was seen in 22 cases (61\%), CPS in 10 cases (28\%), Simple partial seizures in 1 case (2.8\%) and other seizure types in 3 cases $(8.3 \%)$. The association between type of seizure and presence of psychiatric disorder was not statistically significant.It was less than 5 yrs in 22 cases $(61.1 \%)$ and more than 5 yrs in 14 cases $(38.8 \%)$. The association between the age at onset of seizures and presence of psychiatric disorder was found to be statistically significant $(\mathrm{P}<0.0001)$ (table6)

Table 6: Age at onset of seizure and psychiatric disorder

\begin{tabular}{|l|l|l|l|}
\hline Age at onset of seizure & No. of cases & Psychiatric disorder \\
\cline { 3 - 4 } & & Absent & Present \\
\hline$<5 \mathrm{yrs}$ & 33 & 11 & 22 \\
\hline$>5 \mathrm{yrs}$ & 67 & 53 & 14 \\
\hline
\end{tabular}

Duration of epilepsy was <2 yrs in 10 cases (27.7\%), 2 to 6 yrs in 14 cases (38.8\%), 6 to 10 yrs in 11 cases $(30.5 \%)$ and $>10 \mathrm{yrs}$ in 1 case $(2.7 \%)$. Therewas statistically significant association between the total duration of epilepsy and the presence of psychiatric disorder $(\mathrm{P}<0.0001)$.

Table 7: Duration of epilepsy and Psychiatric disorder

\begin{tabular}{|l|l|l|l|}
\hline Duration of epilepsy & \multirow{2}{*}{ no. of cases } & Psychiatric disorder & present \\
\cline { 3 - 4 } & & absent & 10 \\
\hline$<2$ yrs & 54 & 44 & 14 \\
\hline $2-6$ yrs & 33 & 19 & 11 \\
\hline $6-10$ yrs & 12 & 1 & 11 \\
\hline
\end{tabular}




\begin{tabular}{|l|l|l|l|}
\hline$>10 \mathrm{yrs}$ & 1 & 0 & 1 \\
\hline
\end{tabular}

Frequency of seizures in the preceding year was <1 in none of the cases, $1-6$ in 9 cases (25\%), $6-12$ in 12 cases $(33.3 \%)$ and $>12$ in 15 cases $(41.6 \%)$. The association between the frequency of seizures and the presence of psychiatric disorder was statistically significant $(\mathrm{P}<0.0001)$.

b Frequency of seizures and psychiatric disorder

\begin{tabular}{|l|l|l|l|}
\hline Frequency of seizures & \multirow{2}{*}{ No. of cases } & Psychiatric disorder \\
\cline { 3 - 4 } & & Absent & present \\
\hline$<1$ & 5 & 5 & 0 \\
\hline $1-6$ & 50 & 41 & 9 \\
\hline $6-12$ & 24 & 12 & 12 \\
\hline$>12$ & 21 & 6 & 15 \\
\hline
\end{tabular}

20 cases (55.5) were on monotherapy, 15 cases were on polytherapy (41.6\%), 1 case $(2.7 \%)$ was not using any drugs. Out of 35 cases who were using AED, 7cases (19.4\%) were compliant, 28 cases (77.7\%) were noncompliant. There was statistically significant association between the use of AED (monotherapy/ polytherapy), compliance of drugs and the presence of psychiatric disorder.

\section{Discussion}

Out of 100 children with epilepsy included in the present study, 23\% were found to have mental retardation. This is similar to the finding in the previous studies by Camfield et al ${ }^{(7)}$ and Berg et al ${ }^{(8)}$, who reported that approx. 25\% of children with epilepsy have mental retardation. In population-based studies of children with epilepsy, the frequency of mental retardation has been reported to be $24-41 \%$ (Sidenvall et al ${ }^{(9)}$,Sillanpaa ${ }^{(\mathbf{1 0})}$ There is evidence that cognitive deterioration in childhood epilepsy is a progressive process that is independent of medication and begins soon after seizure onset ${ }^{(63)}$.Causes for cognitive impairment in children with epilepsy have been attributed to the effect of ongoing seizures, antiepileptic Drugs and underlying structural brain lesions

Out of 100 cases studied, males were more compared to females, which was similar to that of previous studies. In the present study, males had more psychosocial problems compared to females. In a study of children with a first recognized seizure, Austin et al ${ }^{(11)}$ found that boys with prior unrecognized seizures had more problems than girls, whereas a study of children with chronic seizures (Austin et al ${ }^{(\mathbf{1 2})}$ ) showed that girls with more severe seizures had the most difficulties. Demographic variables like sex, rural/urban residence, socioeconomic status was found to have no statistical significance with the cognitive decline and psychosocial problems, similar to the study by Dunn and Austin ${ }^{(13) .}$

Early age at onset of seizures was associated with more cognitive decline compared to onset of seizures at a later age. This is similar to that seen in other studies by Dunn and Austin' Talukdar et al ${ }^{(\mathbf{1 4})}$ ), Bourgeois ${ }^{(\mathbf{1 5})}$.

There was no statistically significant association between the type of seizure and either the cognitive decline or the psychiatric dysfunction. This correlates with other studies. In a study by Austin et al ${ }^{(\mathbf{1 6})}$, there was no significant association between seizure type and psychosocial difficulties in children with epilepsy of at least one year's duration. In a sample of children with newly onset epilepsy, Austin et alfound that children with partial seizures had more psychosocial problems than children with generalized seizures. Dunn et alreported that seizure type is an inconsistent predictor of behavioralproblems.

Long duration of epilepsy was associated with more cognitive decline and more psychiatric dysfunction, which was statistically significant. This is similar to that in the study by Bourgeois et al ${ }^{(\mathbf{1 5})}$. High frequency of seizures was associated with more cognitive decline. This was statistically significant and similar findings were reported by Festenau et al ${ }^{(\mathbf{1 7})}$, Dunn and Austin' Bourgeois' High frequency of seizures also had statistically significant correlation with psychiatric disturbances. This is similar to the study by Camfield et al who reported that the total impact of pediatric epilepsy on psychosocial function was significantly related to seizure frequency. Similar findings were reported by Dunn et al

Children on polytherapy had very low IQ levels than those on monotherapy. The difference was statistically significant. Similar findings were reported by Festenau et al' Bourgeois et al' Aldenkamp et al, Talukdar et al. Children on polytherapy also had more psychosocial problems compared to those on monotherapy. Causes for the low IQ levels observed in children with polytherapy could be, in addition to the drugs, the underlying seizure variables like longer duration of epilepsy and poor control with high frequency. Children who were compliant had higher IQ levels compared to those who were non-compliant. Noncompliance of AED was also significantly associated with more psychiatric dysfunction. The reasons for the noncompliance of drugs were irregular follow up, non-affordability of drugs, low socioeconomic status. 
It was observed in the present study that $22(22 \%)$ children who were not using any AED had higher IQ levels compared to those who were using AED. This could be explained because many of them had recent onset of seizures with less frequency. Out of 22 cases, only in 1 case the age at onset of seizures was $<5$ yrs. Only 3 cases had $>2$ yrs duration of epilepsy. Only in one case out of 22, the seizures lasted for $>30$ min,Psychosocial problems were observed in 36 cases $(36 \%)$ in the present study. This is 6 times higher compared to the prevalence rate in the general population which is $6 \%$. Similar findings were reported by several other studies.

Rutter et al reported $28.6 \%$ prevalence of psychosocial problems. Davies et al ${ }^{(\mathbf{1 8})}$ reported prevalence rate of psychiatric disorders in children with epilepsy as 37\%. In a population-based study from Rochester, Minnesota, Hedderick \&Buchhalter ${ }^{(19)}$ found comorbid psychiatric disorders defined by DSM-IV in $51 \%$ of children with epilepsy. The figure was reduced to $40 \%$ when children with mental retardation and/or pervasive developmental disorder were excluded. The difference in the percentage of psychosocial disorders among various studies may be related to the difference in the number of subjects and methods used.Compared to the general population, the prevalence rates of learning disorder and emotional disorder are very much increased in children with epilepsy. In the present study, emotional disorders including depression were found in $21 \%$ of children. This was similar to the previous studies. Ettinger et al (20) found that $26 \%$ of children with epilepsy had symptoms of depression. Alwash et al (21) found depression in $23 \%$ of adolescents with epilepsy. Oguz et al (22) found depression in $29 \%$ of epileptic children. Gaitatzis et al reported that mood disorders are the most common culprit (24-74\%), particularly depression (30\%).

The prevalence of various disorders in the present study compared to the general population.

\begin{tabular}{|l|l|l|}
\hline Disorder & Present study & General population \\
\hline Learning disorder & $30 \%$ & $3-10 \%$ \\
\hline Emotional disorder & $21 \%$ & $0.4-8.3 \%$ \\
\hline Conduct disorder & 5 & $1-10 \%$ \\
\hline ADHD & $12 \%$ & $5-10 \%$ \\
\hline Psychosis & $1 \%$ & $0.1-0.2 \%$ (in adolescents) \\
\hline
\end{tabular}

The reason for the increased risk of psychiatric disorders in children with epilepsy may be Transitory Cognitive Impairment(TCI) due to recurrent subclinical epileptiform discharges' social stigma of epilepsy, decreased self-esteem, decreased social interaction, increased parenting stress, the side effects of antiepileptic drugs (sedation, occasional visual blurring, cognitive effects).

\section{Conclusion}

1. Long duration of poorly controlled epilepsy results in higher frequency and severity of Psychosocial disorders.

2. Early identification by cognitive and psychosocial assessment and prompt treatment of the underlying disorders by psychiatrists and psychologists is necessary to decrease the morbidity and increase the quality of life in these children.

3. Early intervention with regard to cognitive dysfunction will help in the better scholastic performance of these children

4. Polytherapy should be advised only when appropriate drug, dose, compliance of monotherapy has been assessed for the control of seizures.

5. Regular neuropsychiatric assessment and good compliance of AED should be stressed upon for a better prognosis in these children.

6. Awareness and education of the caretakers of these children regarding the risk of cognitive and psychiatric disorders is necessary for the better outcome of these children with epilepsy.

\section{References}

[1]. Nelson textbook of Pediatrics, 19th edition

[2]. Cowan LD, BodensteinerJB, Leviton A \& Doherty. Prevalence of epilepsies in children and adolescents. Epilepsia. 1989 JanFeb;30(1):94-106.

[3]. Besag FM (2002). Childhood epilepsy in relation to mental handicap and behavioral disorders. J Child Psychol Psychiatry 2002; 43: 103-131.

[4]. Elger CE, Helmstaedter C \&Kurthen M (2004). Chronic epilepsy and cognition. Lancet Neurology 2004;3: 663-672. Review.

[5]. Rutter M, Graham P \& Yule W. A neuropsychiatric study in childhood. Clinics in Developmental Medicine 1970 volume $35 / 36$.

[6]. BesagFMC. Behavioral aspects of pediatric epilepsy syndromes.EpilepsyBehav. 2004 Feb;5 Suppl 1: S3-13

[7]. Camfield CS, Camfield PR, Veugelers PJ. Death in children with epilepsy: a population-based study. Lancet. 2002 Jun 1;359(9321):1891-5

[8]. Berg AT, Shinnar S, Testa FM, Levy SR, Smith SN, Beckerman B. Mortality in childhood-onset epilepsy. Arch PediatrAdolesc Med 2004; 158:1147-1152. 
[9]. SidenvallR, Forsgren L \&Heijbel J. Prevalence and characteristics of epilepsy in children in Northern Sweden. Seizure; Volume 5, Issue 2, June 1996, Pages 139-146

[10]. Sillanpaa M (1973). Medico-social prognosis of children with epilepsy. Acta PediatricScand (suppl 273): 3-104.

[11]. Austin JK, Harezlak J, Dunn DW. Behavioral problems in children before first recognized seizure. Pediatrics. 2001 Jan;107(1):11522.

[12]. Austin JK, Huster GA, Dunn DW. Adolescents with active or inactive epilepsy or asthma: a comparison of quality of life.Epilepsia. 1996 Dec;37(12):1228-38.

[13]. Dunn DW \& Austin JK (2004). Differential diagnosis and treatment of psychiatric disorders in children and adolescents with epilepsy.EpilepsyBehav. 2004 Oct;5 Suppl 3: S10-7

[14]. Talukdar B, Jayashree K, Srivasthava P.K. Cognitive function and Behaviour in epileptic children of school going age. Indian Pediatr.1999;36:1032-1038.

[15]. Bourgeois BFD, Prensky AL, Palkes HS. Intelligence inepilepsy: a prospective study in children. Ann Neurol1983;14: 438-444.

[16]. Austin JK,Risinger MW \& Beckett LA. Correlates of behavior problems in children with epilepsy. Epilepsia 1992;33: 1115-1122.

[17]. Festenau PS, Johnson CS, Perkins SM, Byars AW. Neuropsychological status at seizure onset in children. Risk factors for early cognitive deficit. Neurology.2009 Aug 18;73(7)526-534.

[18]. Davies S, Heyman I \& Goodman R (2003). A population survey of mental health problems in children with epilepsy. Dev Med Child Neurol 45: 292-295

[19]. Hedderick E \& Buchhalter JR (2003). Comorbidity of childhood-onset epilepsy and psychiatric and behavioral disorders: a population-based study. Ann Neurol 2003 54: (supp17) p.115.

[20]. Ettinger AB, Weisbrot DM, Nolan EE, Symptoms of depression and anxiety in pediatric epilepsy patients. Epilepsia. 1998 Jun;39(6):595-9.

[21]. Alwash RH, Hussein MJ \&Matloub FF. Symptoms of anxiety and depression among adolescents with seizures in Irbid, Northern Jordan. Seizure 2000; 9:412-6.

[22]. Oguz A, Kurul S \&Didrik E. Relationship of epilepsy-related factors to anxiety and depression scores in epileptic children. J Child Neurol2002;17: 37-40. 